\title{
The Investigation Research of Mathematics Classroom Questioning in Junior High School ${ }^{1}$
}

\author{
YE, Lijun \\ College of Mathematics, Hangzhou Normal University, 16 Xuelin St., Xiasha High Education Zone, \\ Hangzhou, Zhejiang 310036, China; Email: yeatsylj@126.com
}

(Received October 7, 2013; Revised December 24, 2013; Accepted December 27, 2013)

Through quantitative analysis of two math classroom videos, combined with the relationship between types of teachers' questioning and students' answering, it is concluded the following problems are in the mathematics classroom teaching:

(1) The time of teachers' questioning is longer, the number is too much, with managerial questions and prompting questions is given priority to;

(2) Teachers' questioning time is longer than students' answering time, comprehensive answer is more, creative answer is little;

(3) In the classroom questioning, students' participation is low; and

(4) There is a significant correlation between types of teachers' questioning and length of waiting time after questions.

In response to these phenomena, we propose strategies as follows: pursuit of timeliness of classroom questioning, reducing inefficient questions, to increase efficient questions, adopting different waiting strategies for different questioning types, to mobilize students' thinking activities, and improving students' participation etc.

Keywords: questioning; questions; strategies

MESC Classification: C23, C70, D40

MSC2010 Classification: 97C70, 97D40

\section{INTRODUCTION}

The most important thing in the interaction between teachers and students is questioning, which is beneficial to achieve different kinds of aims. As a matter of fact, questioning is the center of most activities of mathematics and many process of teaching evaluation (Bell, 1978). Questioning is crucial for exchanging ideas between teachers and students,

\footnotetext{
1 Supported by the Ministry of Education of Humanities and Social Sciences research planning
} fund project (11YJA880139) 
what's more, it is as important as bridge among teachers, textbooks and students ( $\mathrm{Yu}$, 2010). Once Neil postman pointed out that, "all the knowledge we have are come from questioning, that is to say, questioning is a vital way to train brain." An experienced teacher must be good at questioning, questioning is a kind of art; neither the classroom atmosphere can be lived nor the student thinking enthusiasm can be activated unless the trainers use the skill of questioning properly. Through the observation in classrooms and a host of documentary research, I find that there are certain problems in mathematics classroom of junior high school. With continuous deepening of curriculum reform, whether students can make knowledge construction positively is taken more and more seriously by educators. The leading function of teachers plays a dominant role in student's level of involvement, moreover, questioning is the key of implementing teaching and studying at the same time, which is beneficial to achieve many kinds of teaching aims. As a result, it is worth researching on questioning in junior middle school mathematics class since it helps to improve the quality of mathematics class.

\section{OBJECTIVES}

We classified different types of questions appeared and counted them and made a conclusion about the process of teaching in two mathematics classes by the means of video analysis. We tried to find the numbers and types about questions asked by teachers in mathematics class and answers answered by students. In the end, this paper will give some advice about questioning in mathematics class.

\section{METHOD}

After we learned the coding of TIMSS Video Study and studied video case, finally, we decided to use the method of video analysis. We combined field observation and video recording of two mathematics classes and made quantitative research of questioning in mathematics classes, therefore, we got some inspiration and conclusion.

\section{PROCEDURE}

\subsection{The selection of research object}

This article chooses two teachers' classroom video to analyze, who are selected from teachers that are attended, discussed and recorded lectures over a long period of time 
from some schools in Hangzhou. The teaching content of teacher A and teacher B are the basic nature of inequality coming from the second section of the fifth chapter in eight grade mathematics book of Zhejiang Education Edition. These two teachers are young teachers with two or three years experience in teaching. They are working hard and students' achievements in their class are in the general level. As these two teachers actively participate in lectures, observation and evaluation activities, and therefore, whether teachers or students, are adapted to the classroom environment with video. So the video we study showed normal classroom teaching as much as possible.

\subsection{The collection of study data}

During the classroom shooting process, we take on the whole class from the angles of the teacher and students respectively with two cameras. In order to capture the relationship between teachers' questioning and students' response as much as possible, we use audio tools to record the details that text cannot record. Then we watch the content of the shot repeatedly, and record the whole teaching process in the form of text. We record the discourse of teachers and students, besides; we also record the beginning, ending time and pause time of teachers' teaching and students' response during the whole teaching process, including the corresponding time of all teaching activities in the class. And this article counts the types of teachers' questioning, response time and number of times of students' response. Then this article draws relevant conclusions through combining the collection and collation of such data with statistical analysis.

\subsection{The analysis of study data}

After recording and counting the two classes, we make quantitative analysis of it. We make comparison and statistics of each class of the classroom questioning, calculate the percentage of them in class teaching respectively and estimate which question is valid.

\subsubsection{Types of teacher's questioning}

According to questions' role and different levels of cognitive level, we divide questions into management, memorizing, prompt, repetition, comprehension, evaluation and other six types on the basis of Bloom's (1956) classification of the six cognitive domain level (knowledge, comprehension, application, analysis, synthesis, and evaluation) and the role and purpose of Math teachers' questions in class (Ye, $\mathrm{Hu} \& \mathrm{Si}, 2010)$. Managerial questioning: In order to maintain classroom's discipline and make teaching orderly, teacher ask questions to students, which has nothing to do with the classroom knowledge. Memorial questioning: Questions about basic facts and materials, such as concepts, formulas, theorems, nature, steps, procedures' retelling and questions about Simple arithme- 
tic, which students don't need to comprehend.

Repetitive questioning: In order to doubt or emphasize students' answer, teacher repeats students' answer and ask new question, which can get feedback of the extent of students' learning.

Prompting questioning: Teacher inspire students thinking correctly with relevant knowledge, or in order to complete the whole process of guidance, teacher prompt students about problem-solving steps.

Comprehensive questioning: It's the questioning that needs to combine the knowledge of certain thinking, induction and summary.

This kind of question sometimes put forward higher requirements for students based on prompting questioning. Evaluated questioning: Such questions ask students to judge, which is on the basis of that students can make decisions according to certain standards.

\subsubsection{The type of students'answer}

According to the cognitive complexity of students' answer, we can divide student's answer into five types, such as no answer, mechanical answer, memorial answer, comprehensive answer, creative answer. No answer means that students did not answer the teacher's questions. Mechanical answer means that students' answer is the answer that teacher or other students have already given, students don't need to recall the existing knowledge to answer teacher's question.

Memorial answer means that students answer teacher's question by recalling the existing knowledge. Comprehensive answer means that students answer teacher's question after thinking and understanding. Creative answer is the answer that is on the basis of that student from their ideas creatively with the existing knowledge (Si \& Ye, 2011).

\section{RESULT AND IMPLICATIONS}

\subsection{Teachers' questioning}

The time of teachers' questioning is longer, the number is too much, with managerial questions and prompting questions is given priority to.

Questioning is an effective method of mathematics teaching. Both of the two teachers attach great importance to questioning in class. As shown in Table 1, teacher A asked 153 questions to students, whose time account for one-third of the entire class time; teacher B ask students 102 times, and the time of questioning account for $45.24 \%$ of the whole lesson time. And the two teachers ask questions to students 127.5 times on average and 
the average time for questioning account for 36.26 percent of the whole lesson time. As a statistical matter, we can learn that the time of teachers' questioning is too long and both of the numbers of the two teachers' questioning are over 100. Especially teacher B, whose time of questioning occupy nearly half of the entire class time. It indicates that teachers may focus more on quantity than quality about questioning in class, which may make it hard for students to obtain complete knowledge.

As shown in Figure1, managerial questioning and prompting questioning accounted for a large proportion in the two teachers' questioning. Especially teacher B asked manageable question 31 times and asked prompting questioning 44 times, which accounted for $73.53 \%$ of all questions.

Through statistics, we can find that the two teachers asked little questions that has opening answer or encourage students to analyze problems. Teacher A didn't ask estimated question and teacher B asked twice, which only accounted for $1.96 \%$ of all the questions. It indicates that the effectiveness of teachers' questioning is insufficient in the mathematics classroom and most questions only base on low-level cognitive level of the students which can hardly stimulate students' interest in learning and thinking.

Table1. The time distribution and times of questioning in the two classes

\begin{tabular}{cccc}
\hline Teacher & The number of questioning & The time of questioning & Percentage of time \\
\hline A & 153 & 12 & $27.27 \%$ \\
\hline B & 102 & 19 & $45.24 \%$ \\
\hline
\end{tabular}

Note: The whole time of teacher A's class is 44 minutes and the whole time of teacher B's class is 42 minutes.

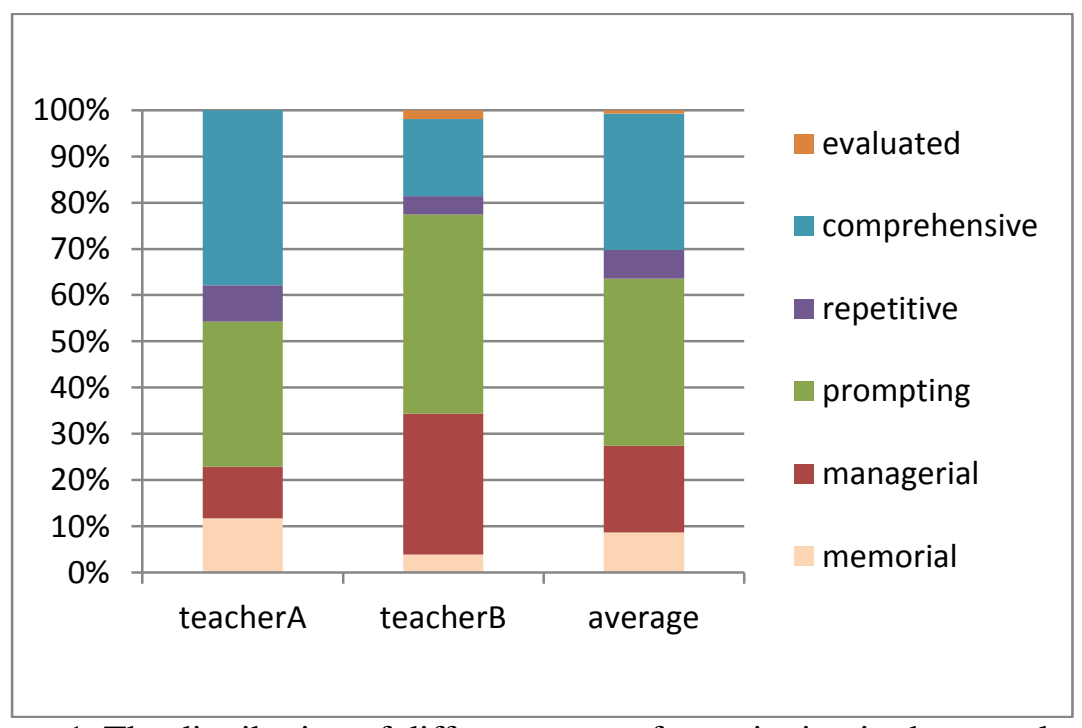

Figure 1. The distribution of different types of questioning in the two classes 


\subsection{Teachers' questioning time vs. students' answering time}

Teachers' questioning time is longer than students' answering time, comprehensive answer is more, creative answer is little.

According to the statistical data in Table 1 and Table 2, we can learn that teacher's questioning takes more time than students' answer obviously, especially teacher B whose time of questioning is twice the time of students' answer. It can be found from Figure2 that most students' answer is comprehensive answer followed by mechanical answer and memorial answer. In teacher A's class, students answer comprehensive answer 76 times accounting for $49.67 \%$ of the all answers, while students answer comprehensive answer 60 times in teacher B's class, which account for 58.82\%. In the meantime, creative answers account for small percentage. Especially in teacher A's class, teacher A asks 153 times while students answer 133 times with no creative answer. In mathematics teaching, questioning is an important part of teaching process, the teacher almost run through the whole process by questioning. However, if teacher's questioning takes much more time than students' answer, it's difficult for students to think out creative answers and inspire effective thinking, which makes what students learn is not so much and affect the efficiency of whole class (Si \& Ye, 2010).

Table 2. The time distribution and times of students' answer in the two classes

\begin{tabular}{cccc}
\hline Teacher & $\begin{array}{c}\text { The number of students' an- } \\
\text { swer (exclude no answer) }\end{array}$ & $\begin{array}{c}\text { The time of students' } \\
\text { answer }\end{array}$ & Percentage of time \\
\hline A & 133 & 9 & $20.45 \%$ \\
\hline B & 98 & 9 & $21.43 \%$ \\
\hline
\end{tabular}

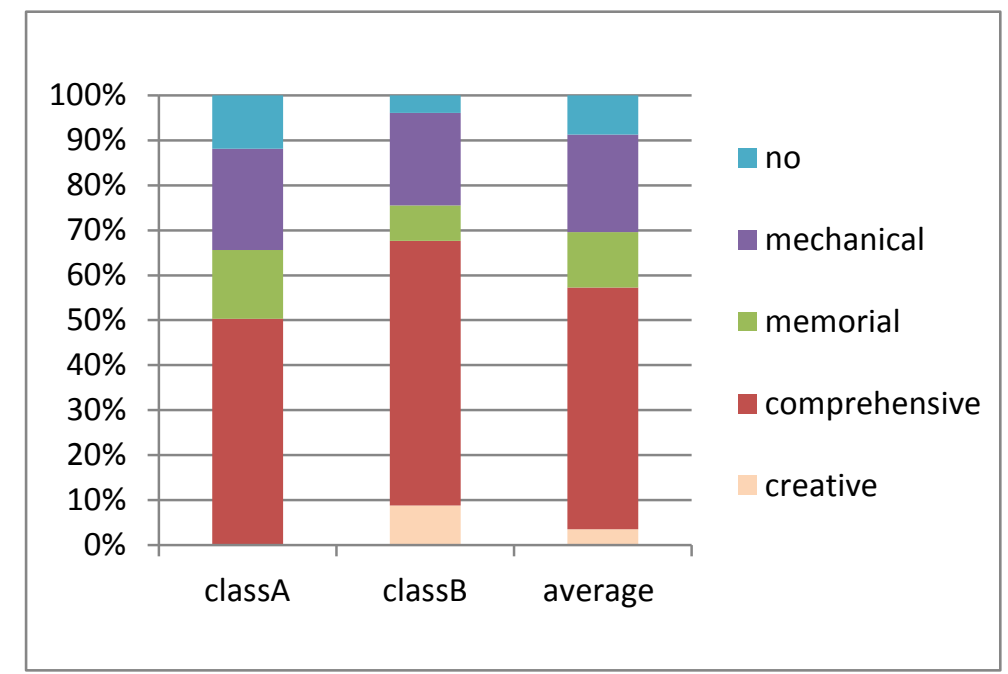

Figure2. The distribution of different types of answer in the two classes 


\subsection{Students' participation}

In the classroom questioning, students' participation is low.

The interaction and dialogue of teacher and students is the main form of classroom activities in mathematics teaching (Ye \& Si, 2011). The essence of mathematics teaching and the process of mathematics learning is that students can take the initiative to construct mathematical cognitive structure under the guidance of teachers, and make themselves get all-round development (He, 2002; Li \& Shi, 2005). It can be found from the statistics of Table 3 and Table 4 that the average number of a class of students' individual response is 45.5 which account for about $1 / 3$ of the total average response times (127.5 times that we can learn from Table 1). The majority of students' response in the classroom belongs to collective response or random response. In the stage of the teaching of new knowledge, the average number of the students who participate in the response is 2, while the average number of teacher's questioning is 42 , which can see that the proportion of students' participation in answering is not high and students' enthusiasm is not well mobilized. Meanwhile, during the stage of practice of the class, the average number of the students who participate in the response is far away from the average number of teacher's questioning. This shows that teacher ask questions frequently ,but the degree of students' participation in class questions is low, because teacher's questioning lack of timeliness that cannot really inspire students' thinking.

Table 3. Students' participation in answer of different teaching link

\begin{tabular}{lcccc}
\hline Teaching link & $\begin{array}{c}\text { The average } \\
\text { number of par- } \\
\text { ticipants }\end{array}$ & $\begin{array}{c}\text { The average } \\
\text { number of partic- } \\
\text { ipating }\end{array}$ & $\begin{array}{c}\text { The average par- } \\
\text { ticipation time } \\
\text { (minutes) }\end{array}$ & $\begin{array}{c}\text { The average per- } \\
\text { centage of time }\end{array}$ \\
$\begin{array}{c}\text { introduction } \\
\text { new knowledge } \\
\text { teaching }\end{array}$ & 0 & 0 & 0 & $0.00 \%$ \\
$\begin{array}{c}\text { class-exercise } \\
\text { summary }\end{array}$ & 18.5 & 5.5 & 0.63 & $1.49 \%$ \\
& 0 & 0 & 6.12 & $14.43 \%$ \\
aggregation & 20.5 & 45.5 & $0.00 \%$ & $15.92 \%$ \\
\hline
\end{tabular}


Table 4. Teacher's questioning of different teaching link

\begin{tabular}{cccc}
\hline Teaching link & Number of average & $\begin{array}{c}\text { The average time } \\
\text { (minutes) }\end{array}$ & $\begin{array}{c}\text { The average percent- } \\
\text { age of time }\end{array}$ \\
\hline Introduction & 4 & 0.84 & $1.98 \%$ \\
New knowledge teaching & 42 & 5.89 & $13.88 \%$ \\
class-exercise & 80.5 & 8.82 & $20.79 \%$ \\
Summary & 0.5 & 0.08 & $0.19 \%$ \\
aggregation & 127 & 15.63 & $36.84 \%$ \\
\hline
\end{tabular}

\subsection{Correlation between types of teachers' questioning and length of waiting} time after questions

There is a significant correlation between types of teachers' questioning and length of waiting time after questions.

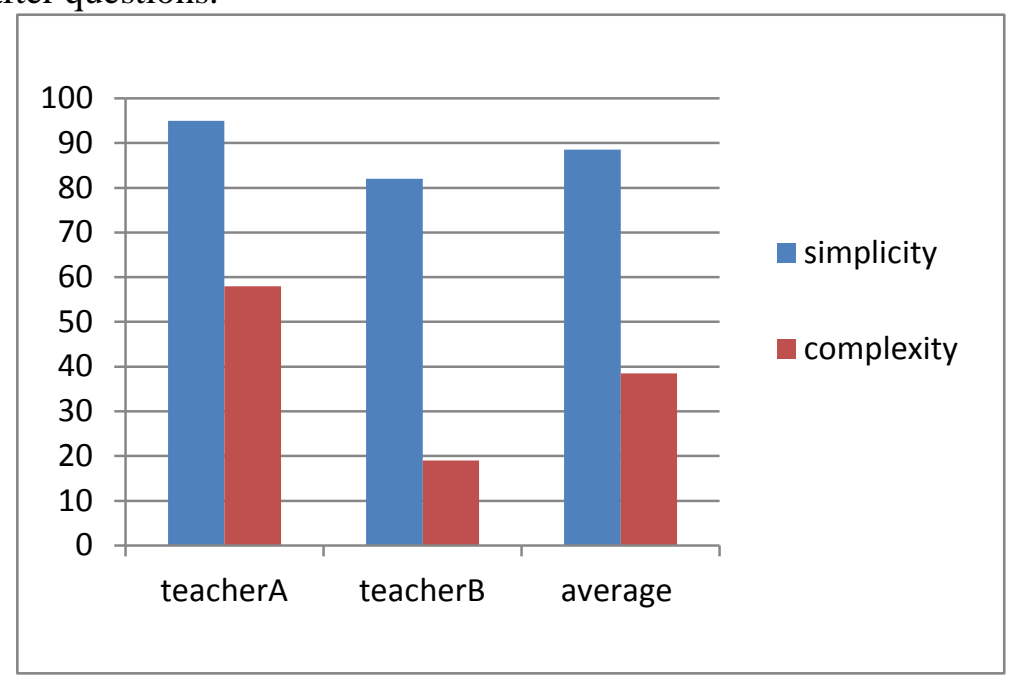

Figure 3. The distribution of difficulty of the questionings in the two classes

According to the 6 types of questionings and the different difficulty of the questionings, teachers' questionings can be divided into "simplicity questioning" and "complexity questioning". Simplicity questioning includes managerial questioning, Memorial questioning, repetitive questioning and prompting questioning; complexity questioning in- 
cludes comprehensive questioning and estimated questioning (Ye \& $\mathrm{Li}, 2011$ ). It can be seen in Figure 3 that most teachers' questionings are simplicity questionings which account for $62.09 \%$ and $81.19 \%$ respectively of the whole number of questionings.

According to the distribution of two teachers waiting time of questioning, as shown in Table 4 and Table 5, we can find that the average time of teacher's questioning is 15.63 minutes, while the average waiting time for students is only 0.52 minutes. The waiting time after questioning is too short for students to think adequately.

Table 5. The distribution of waiting situation after questioning of the two classes

\begin{tabular}{cccc}
\hline & Waiting time(minutes) & Waiting times & $\begin{array}{c}\text { The percentage of } \\
\text { waiting time }\end{array}$ \\
\hline Teacher A & 0.53 & 4 & $1.25 \%$ \\
Teacher B & 0.50 & 7 & $1.18 \%$ \\
Average & 0.52 & 5.5 & $1.22 \%$ \\
\hline
\end{tabular}

We use SPSS to do Pearson correlation detection of the time of teacher's questioning and the waiting time, the detection results are shown in figure 4 :

\section{Correlation}

\begin{tabular}{|c|c|c|c|}
\hline & & Questioning & Time \\
\hline \multirow[t]{2}{*}{ Questioning } & $\begin{array}{l}\text { Pearson's correlation } \\
\text { coefficient }\end{array}$ & 1 & $1.000^{* *}$ \\
\hline & Significant (bilateral) & 4 & 2 \\
\hline \multirow[t]{2}{*}{ Time } & $\begin{array}{l}\text { Pearson's correlation } \\
\text { coefficient }\end{array}$ & 1. $000^{* *}$ & 1 \\
\hline & Significant (bilateral) & 2 & 2 \\
\hline
\end{tabular}

Figure 4. Pearson correlation test results

As can be seen from Figure 4, there is a significant correlation between the type of teacher's questioning and the waiting time after questioning. In other words, Teachers adopt different strategies of waiting time for different types of problems. The waiting time is short for some simple questions, and the waiting time is long for some complex questions, Which can give students enough time to think and enhance their understanding level of problems. 


\section{STRATEGIES OF IMPROVING THE EFFICIENCY OF TEACHERS' QUESTIONING IN CLASSROOM.}

\subsection{Pursue timeliness of classroom questioning, reducing inefficient questions and increasing efficient questions}

Conversation system between a teacher and a student contains the activity of questioning and answering, which aims at achieve teaching purpose. It is pointless and worthless if the instructors put emphasis on pursue more questioning and answering so as to making class seem to be active rather than accomplishing teaching task. Therefore, based on different teaching aims and different teaching tasks and different students, teachers should choose different types of questioning so that students can be inspired on different cognition levels of responses. In the meantime, teachers should reduce inefficient questions and increase efficient questions, in which motivate students to think positively, at last, students can be guided to the contents of key and essence. Not only can students be improved to study mathematics more efficiently, but also they can boost their confidence in learning mathematics and acquire a strong sense of efficiency (Wang, 2010).

\subsection{Guiding students to take different response mode for different types of ques- tions}

The famous Russian psychologist Vygotsky divide the human's cognitive structure into three gradations- "Zone of known", "Zone of Proximal Development", and "zone of unknown" (Yu, 2005). The cognitive level of human is a constant process going forward circularly transformation and spirally. Teachers can manage the class are inclined to control the class discipline more strictly and put forward questions either semi-simple or complicated that can motivate the higher cognitive level of students. In the meantime, if every student can be questioned equally rather than force to answer, they will be able to concentrate better on thinking, learning and participating into the education activity, thus creating higher cognition answer (Wigle, 2002). Therefore, on purpose of promote the students' ability of thinking and understanding, the questions that teacher put forward need to correspond with the cognitive level of students and at the students' zone of proximal development.

\subsection{Encourage students to participate in answering questions enthusiastically}

Mathematics teaching is a process of teaching made of mathematics activities, which prompts interaction and development among students, and even between students and 
teachers (Zhong, 2009). As the leader and organizer of classroom teaching, in the process of questioning and answering and thinking teachers manage to inspire students, encourage them participate in teaching activities so as to boost their confidence in learning mathematics when experiencing to solve problems, as a result, Construct the understanding of knowledge. As it is shown in figure 3 and figure 4, the more questions teachers asked, the less answers students offered, volunteers who wants to answers questions initiatively lowered dramatically. In particular, in the procedure of teaching new knowledge and classroom exercise, the degree of participation among students is low. Therefore, teachers should encourage students participate in class activities enthusiastically properly, show their ideas so that students can play a key role in class. Meanwhile, teachers should aim at improving students to study efficiently, which makes students acquire knowledge in the process of think positively and independently (Qiao, Li, Du, Luo \& Liu, 2010).

\subsection{Adopt different waiting strategy for different types of questions.}

In the process of teaching in classrooms, teachers can question properly so as to making students regulate their thinking strategy, having their own ideas to certain problems, implementing self monitoring (Guo \& Song, 2008). My research has shown that there is obvious linear relation between the type of questions and the length of time after asking questions. To make mathematics teaching more efficient, teachers should give students enough room and time to think independently when they offering questions and inspiring students, that is, waiting for students' answers. This is because mathematics thinking can only be happened in an individual, which cannot be replaced, in the meantime, information integration needs time (Bai \& Han, 2011). Therefore, teachers should give students different time in accordance of difficulty of questions and degree of cognition so that teachers can arouse the enthusiasm of thinking and improve their level of thinking and degree of participation. Only in this way, students' thinking ability can be activated with a maximum improvement.

\section{REFERENCES}

Bai, Gaiping \& Han, Longshu (2011). Case Study of the Comparison between the Expert and Empirical Mathematics Teachers' Abilities of Asking Questions in Classroom Teaching (In Chinese). J. Math. Educ. (Tianjin) 20(4), 16-19.

Bell, F. H. (1978). Teaching and Learning Mathematics (In Secondary Schools). Dubuque, Iowa, USA. [Chinese Edition: Xu, Zhensheng \& Guan, Chengzhong (Translators) (1987). The mathematics teaching and learning of middle school (volume two). Beijing: Education Science Press.] 
Bloom, B. S. (Ed.) (1956). Taxonomy of Educational Objectives: The Classification of Educational Goals; Handbook I, Cognitive Domain. New York: Longmans

Guo, G. \& Song, X. (2008). Contrast Study on "Problem-using Teaching" in Mathematics Classroom between "Novice-Practitioner-Expert" Teachers (In Chinese). J. Math. Educ. (Tianjin) 17(2), 51-54. ME 2008e.00163

He, Xiaoya (2002). Instructional Strategies on Constructing well Mathematical Cognitive Structure (In Chinese). J. Math. Educ. (Tianjin) 11(1), 24-27.

Li, Jibao \& Shi, Kefu (2005). Characters of Mathematics Cognition Structure and Researching to Process of Mathematics Study (In Chinese). J. Math. Educ. (Tianjin) 14(3), 80-82. ME 2006a.00129

Qiao, Ximin; Li, Junzhuang; Du, Weijie; Luo, Junli \& Liu, Xiaomin (2010). Research of Efficient Math Teaching in Class (In Chinese). J. Math. Educ. (Tianjin) 19(5), 84-86.

$\mathrm{Si}$, Haixia \& Ye, Lijun (2010). Comparative Study of the Differences between the New and Experienced Teachers in the Teaching of abstract generalization of Mathematics (In Chinese). $J$. Math. Educ. (Tianjin) 19(6), 53-55. ME 2013b.00259

(2011). Analysis of Student Engagement in Middle School Mathematics Classroom Based on the Video Case (In Chinese). J. Math. Educ. (Tianjin) 20(4), 10-12.

Ye, Lijun \& Si, Haixia (2011). Study of Teachers' Language of Instruction Based on Videos of the Algebra Classrooms-Such as Two Cases of "The Multiplication and Division of the Fractions" (In Chinese). J. Math. Educ. (Tianjin) 20(1), 42-44.

Wang, Guangming (2010). Attributions of High-efficiency Mathematics Teaching Behavior (In Chinese). J. Math. Educ. (Tianjin) 19(5), 75-79.

Wigle, Stanley E. (2002). Higher quality questioning. Education Digest 65(4), 62-64.

Ye, Lijun; Hu, Qinzhu \& Si Haixia (2010). Study on Questioning of Algebra Classroom under the Background of the Video Analysis (In Chinese). J. Math. Educ. (Tianjin) 19(3), 32-34.

Ye, Lijun \& Li, Yan (2011). Study Questions in the Statistics Classroom by Video Analysis (In Chinese). J. Math. Educ. (Tianjin) 20(5), 52-54.

Yu, Wensen (2010). Effective preparation, lectures, observation and evaluation. Fujian: Fujian Education Press.

Yu, Zhenqiu (2005). Vygotsky's theory of education election. Beijing: People's Education Press.

Zhong, Xiuying (2009). Mathematics Activities' Connotation, Features and Teaching Inspiration (In Chinese). J. Math. Educ. (Tianjin) 18(4), 23-26. 